\title{
Cengestao \\ O desenvolvimento e o entrelaçamento entre bibliografia, bibliometria e política no Brasil
}

\author{
Giulia Crippa \\ Doutora, Universidade de Bolonha, Campus de Ravenna, Itália; \\ giulia.crippa2@unibo.it
}

\begin{abstract}
Resumo: Esse artigo visa estudar o percurso e o estado atual dos estudos bibliográficos no Brasil, com base na proposição de que a natureza da bibliografia, que a caracteriza em sentido disciplinar e crítico, não se limitam ao fato de ser uma enumeração de documentos ou de servir como esquema de sua realidade no sistema, mas deve servir também como mapa a ser consultado em relação aos mesmos. Para isso, foi necessário reconstituir o contexto histórico que permite a compreensão da relação entre políticas nacionais e políticas da informação ao longo do século XX. Descobrimos, dessa maneira, que as escolhas de investimentos que privilegiaram quase unicamente a pesquisa científico-tecnológica tornaram a bibliometria a forma privilegiada de estudo e aplicação bibliográfica no país pelo menos até os primeiros anos do século XXI. Nessa pesquisa, realizada pela indagação histórica das fontes, foram encontrados e tratados alguns dos grandes protagonistas dos processos de implantação das metodologias bibliográficas e bibliométricas, como Lydia Sambaquy e Edson Nery da Fonseca. Nossa hipótese é de que houve, desde a época do Estado Novo, um entrelaçamento evidente e explícito entre as políticas nacionais voltadas para visões cientificistas de modernização e políticas de informação.
\end{abstract}

Palavras-chave: Bibliografia. Bibliometria. Lydia Sambaquy. Edson Nery da Fonseca. Políticas da Informação.

\section{Introdução}

A proposta deste artigo é compreender como, no contexto brasileiro do século $\mathrm{XX}$, se desenvolveram os estudos no campo da bibliografia, com base em uma série de considerações históricas e na revisão da literatura produzida no Brasil nos últimos anos. A partir dos resultados de uma pesquisa realizada nas principais bases de dados brasileiras da área de Ciência da Informação e Biblioteconomia (CRIPPA, 2018), percebemos que, desde o final do século XIX até hoje, existem publicações bibliográficas cuja periodicidade não é constante, enquanto, a partir da década de 1970, a produção é quase inexistente. Sentimos a necessidade de refletir sobre as razões pelas quais naquela década muitos dos trabalhos e artigos publicados em revistas da área se voltaram para a concepção 
e aplicação da bibliometria, tornando-a praticamente a única perspectiva legítima dos estudos bibliográficos. No entanto, a partir do início dos anos 2000, pode ser observada uma mudança nesta tendência, quando se observam algumas aberturas do campo da Ciência da Informação para discussões relacionadas à memória e à própria bibliografia, buscando trajetórias mais amplas do que os estudos métricos. Veremos, ao longo de nossa discussão, como o desenvolvimento da Ciência da Informação no Brasil provocou estas tendências.

O percurso apresentado busca relacionar as políticas nacionais brasileiras do século XX com as políticas de informação, que são enfocadas pelas primeiras como estratégicas para o desenvolvimento e a modernização do país. Nessa perspectiva, nossa hipótese é a seguinte: a tendência brasileira de restringir e sobrepor os estudos bibliográficos aos estudos métricos se fundamenta nas políticas que visavam a modernização do Brasil durante os anos da ditadura militar (1964-1984), em que constata-se que a orientação para os estudos métricos permitiu um maior controle da produção científica e dos investimentos em pesquisa também de um ponto de vista ideológico. A fundamentação de ideais de desenvolvimento científico-tecnológico se encontra durante o governo autoritário de Getúlio Vargas (1938-1945), que origina o Instituto Brasileiro de Bibliografia e Documentação (IBBD) em 1954.

Não nos parece coincidência que no campo da Ciência da Informação que no Brasil assumiu conotações diretamente ligadas à produção científica e tecnológica já nos anos 50 - somente no início dos anos 2000 se abriram espaços de pesquisa e discussão para tópicos ligados à leitura, à memória e, finalmente, a reflexões teóricas e práticas sobre a bibliografia. São anos que coincidem com governos preocupados com melhorias na educação e cultura, lembrando que o Brasil ainda está entre os países cuja distribuição de renda é profundamente desigual. Os incentivos de apoio e desenvolvimento de equipamentos culturais, considerados ferramentas de desenvolvimento social, são visíveis durante os dois mandatos presidenciais de Inácio Lula da Silva (entre 2003 e 2011) e nos mandatos de Dilma Rousseff (de 2011 a 2016, sendo o segundo interrompido pelo impeachment da mesma). No entanto, as políticas culturais desenvolvidas naqueles anos não atingiram efetivamente a população mais necessitada e, 
ainda, não tiveram tempo de se enraizar nas realidades territoriais. Nos anos entre 2003 e 2014 um conjunto de políticas sociais, embora ainda inadequado, permitiu certo desenvolvimento de iniciativas relacionadas a bibliotecas e práticas de leitura, por meio da participação ativa de usuários e bibliotecários, como a construção de Planos Municipais do Livro e da Leitura (PMLL), que deveriam ter sido incluídos no Plano Nacional (PNLL) ${ }^{1}$. Este último foi criado em 2006 pelos então Ministros Gilberto Gil e Fernando Haddad, com o intuito de estabelecer políticas públicas centradas no livro e na leitura e, sobretudo, nas bibliotecas (e na formação de mediadores), reconhecendo o papel essencial que elas desempenham para o desenvolvimento social e da cidadania, na dimensão de uma sociedade mais justa. Embora ainda oficialmente em andamento, esses planos encolheram bastante por causa da redução brutal do orçamento previsto para eles. Também a criação dos chamados Pontos de Cultura, sempre concebidos e inaugurados durante o ministério de Gilberto Gil, destinados a desempenhar uma função de hubber culturais, capazes de operar por meio de uma estrutura ligada às tecnologias digitais e à inclusão da população para seu uso, tinham um papel bastante interessante no campo das políticas culturais e de informação. Infelizmente, a forte crise institucional e social que varreu o Brasil desde 2016 reduziu novamente o investimento no setor cultural. Como se vê, estamos falando de um país em que é possível observar claramente a relação direta estabelecida entre política nacional e políticas de informação e cultura.

Em 1954, quando foi fundado o IBBD, é possível observar sua inserção em um projeto político de desenvolvimento e modernização planejado por Getúlio Vargas, suicida no mesmo ano. A criação e existência do IBBD se tornou possível, como veremos no artigo, pelo apoio financeiro da UNESCO, no contexto das relações estabelecidas entre Brasil e Estados Unidos definidas como "Política da Boa Vizinhança" (TOTA, 2000), parte da perspectiva (na época compartilhada entre os dois países) da "Doutrina Monroe", fundada no princípio da "América para os americanos".

Em 1976, em plena ditadura militar, o IBBD foi transformado em um instituto de pesquisa federal, diretamente ligado ao Ministério da Ciência e Tecnologia, o Instituto Brasileiro de Informação em Ciência e Tecnologia 
(IBICT). A transformação do IBBD em IBICT deve-se ao desenvolvimento das tendências do IBBD, cujos representantes direcionaram claramente e de forma crescente os interesses bibliográficos para produções mais estritamente científico-tecnológicas, que abrangiam áreas consideradas estratégicas em uma perspectiva explícita de ideais de desenvolvimento.

Segundo Araujo (2006), na década de 1970 assistimos a uma ampla proliferação de estudos bibliométricos na literatura científica. Nos estudos publicados entre o final da década de 1990 e o início da década de 2000, o autor observa a evolução no uso cada vez mais frequente de dados bibliométricos como indicadores de produção científica, a serviço de escolhas de planejamento e investimentos em pesquisa. Se, por um lado, há um denominador comum internacional nos interesses bibliométricos, é necessário recordar, mais uma vez, que os interesses políticos dos governos militares que se sucederam pelo menos até 1984 não se refletem apenas nas políticas de pesquisa, mas também têm uma implicação mais sutil, ligada mais precisamente às atividades de controle ideológico implementadas durante esses anos. A bibliometria, nesse sentido, adquire um papel também como ferramenta de controle da produção ideológica no campo acadêmico e de pesquisa. Esses processos, como veremos, tendem a orientar o caminho que leva às formulações epistemológicas da Ciência da Informação brasileira, muitas vezes em conflito e em detrimento da Biblioteconomia, essa última identificada por uma função mais dirigida ao desenvolvimento social. De fato, a Ciência da Informação brasileira não manifesta qualquer interesse, dos anos 70 aos anos 2000, para questões de memória e de reflexão bibliográfica como conjunto de conhecimentos voltados para interesses sociais e/ou patrimoniais. As discussões sobre memória no campo da Ciência da Informação são, assim, bastante recentes e encontram espaço nessa área justamente nos anos 2000 (OLIVEIRA et al., 2017), quando a política nacional, como apontado anteriormente, propõe maiores investimentos no campo da cultura. Paralelamente, observa-se um renovado interesse em estudos bibliográficos. Essas novas escolhas de políticas de pesquisa e informação, portanto, parecem coincidir com a tentativa de afirmar plenamente alguns princípios democráticos, através de uma política nacional baseada em 
princípios de inclusão social que se reflete nas políticas culturais e informacionais. Os próprios estudos métricos, dentro desse novo contexto, assumem o papel de contribuir para o desenvolvimento do conhecimento em uma vertente mais ampla, através da proposição de modelos que entrelaçam suas discussões com a criação de ferramentas bibliográficas efetivas, não só ligadas a mediações voltadas às agências de fomento e às suas escolhas políticoinstitucionais, mas também em relação ao público e usuários.

Os estudos sobre métricas, tão predominantes no Brasil se comparados com outros aspectos do campo da bibliografia, parecem ter buscado a substituição de um conjunto mais amplo de reflexões. Estudos métricos, como parte do pensamento bibliográfico, acabaram se tornando seu único elemento constitutivo. Desta forma, a abordagem já difícil por parte dos usuários brasileiros aos registros de conhecimento, torna-se ainda mais complexa em suas pesquisas informacionais. A falta de interesse na bibliografia como mediação, como ponto de acesso essencial à produção intelectual e científica, mudou até o cenário ligado às funções da Biblioteca Nacional $(\mathrm{BN})$ do Rio de Janeiro. No Brasil, o depósito legal de todas as publicações nacionais está em vigor, e uma das tarefas da BN foi, por vários anos, a elaboração anual da Bibliografia Nacional. Desde 1997, no entanto, essa compilação não é mais realizada, pois aparentemente se estabeleceu uma sobreposição entre a bibliografia e o catálogo. O catálogo, no entanto, é apenas parcialmente identificado com a bibliografia, pois na verdade é um produto dela. Em um lugar onde, teoricamente, todas as publicações são depositadas, o catálogo é visto como coincidente com a bibliografia. Esta escolha não elimina alguns aspectos que tornam mais complexas as operações de acesso e recuperação da informação bibliográfica completa do que foi efetivamente produzido (basta pensar no problema representado pela literatura cinzenta).

A bibliografia, entendida como "um dos setores do complexo sistema social" (BALSAMO, 2017, p. 11) recebeu pouca atenção, reduzindo-se às aplicações técnico-práticas da catalogação de livros. No entanto, em nossa opinião, as grandes mudanças provocadas pelas novas tecnologias forçam, paradoxalmente, uma reflexão epistemológica ao mesmo tempo antiga e 
moderna sobre a ordem das representações do mundo de uma forma muito mais ampla do que aquela imposta pela informação científica e tecnológica. Nesse artigo, buscamos:

1) compreender o motivo da escassez de publicações especificamente bibliográficas e a escassez de obras publicadas sobre o tema da bibliografia, através de uma breve revisão histórica sobre o surgimento das práticas bibliográficas relacionadas à imprensa no Brasil, para, em seguida,

2) oferecer um panorama vinculado ao desenvolvimento do IBBD, implementado em 1954 e transformado, em 1976, no IBICT. Neste caminho,

3) tentaremos ilustrar, através da figura chave de Edson Nery da Fonseca, entre os fundadores tanto do IBBD como do IBICT, algumas razões históricas e culturais que levaram as políticas de informação a vincular a bibliografia quase exclusivamente à faceta bibliométrica.

O que procuramos é desenhar um caminho que permita compreender as razões por trás das escolhas de investimentos em pesquisa e divulgação que dizem respeito tanto à reflexão quanto à construção da bibliografia entendida como mapa e índice de literatura, ciência e cultura, como atividade fundada e expressa através de testemunhos documentários, de qualquer natureza sejam, como prova ordenada das notícias sobre tudo o que já foi escrito e publicado ou reproduzido, independentemente de ser acessível a todos ou a ninguém (SERRAI, 2001).

\section{Histórico das práticas bibliográficas no Brasil}

Ao contrário de outros países latino-americanos, em que o campo bibliográfico se implementa já na era colonial, o caso brasileiro, cuja história está ligada não ao império colonial espanhol, mas ao português, apresenta peculiaridades que nos cabe sinalizar. No caso do México, por exemplo, a história da imprensa (e, portanto, do desenvolvimento de práticas bibliográficas) remonta a 1538, coincidindo com a fundação da Universidade da Cidade do México, enquanto no Peru a imprensa foi introduzida em 1584 e, provavelmente no mesmo ano, em 
Manila. (LAFAYE, 2002). Nas terras das colônias ultramarinas portuguesas, no entanto, é somente em 1808 que a coroa portuguesa autoriza a impressão. Dois anos depois, a biblioteca real de Lisboa chega ao Brasil (SCHWARTZ, 2002). Até então, havia bibliotecas privadas e eclesiásticas pertencentes a várias ordens religiosas (especialmente beneditinos e franciscanos), governadas por práticas bibliotecárias cujos estudos ainda são incompletos e pouco conhecidos (MORAES, 2006).

Os primeiros trabalhos bibliográficos sistemáticos sobre os livros da tipografia real são os Anais da Imprensa Nacional do Rio de Janeiro de 1808 a 1822, compilados por Alfredo do Valle Cabral em 1881, com um suplemento de 1823 a 1831. O autor compôs um estudo que, ainda hoje, é referência para conhecer o funcionamento da imprensa e sobre o sistema da censura na época. (CABRAL, 1998). A compilação de Cabral tenta reconstruir o conjunto de títulos publicados utilizando diferentes fontes, dentre as quais os registros das coleções da Biblioteca Nacional, os arquivos da Tipografia Nacional (perdidos após um incêndio em 1911) e os anúncios de livros publicados nos vários jornais e revistas em circulação na época. Trata-se, portanto, de um verdadeiro trabalho de pesquisa que resultou em uma bibliografia fundamental, ainda que, segundo o próprio autor, "devido à dificuldade de não encontrar alguns dos trabalhos publicados na época, não é uma obra completa" (CABRAL, 1998, p. 9). Embora o depósito legal tenha sido estabelecido no Brasil em 1847, foi somente em 1886 que a Biblioteca Nacional publicou (apenas por dois anos) o Boletim das mais importantes aquisições feitas pela Biblioteca Nacional, organizado por João Saldanha da Gama (1835-1889), chefe da seção de imprensa da Biblioteca em 1876 e diretor da mesma desde 1882. A partir desta bibliografia considerada a primeira fase do subsequente Boletim Bibliográfico - quatro edições foram publicadas por ano. A necessidade de publicar um boletim bibliográfico que fornecesse os relatórios dos materiais recebidos conseguiu transformar em produção regular o Boletim Bibliográfico da Biblioteca Nacional, criado em 1918 pelo então diretor da BN, Manuel Cícero Peregrino da Silva, e foi publicado entre os anos de 1918 e 1921, com 14 volumes produzidos de acordo com os padrões do Instituto Internacional de Bibliografia desenhados 
por Paul Otlet e Henri La Fontaine, com informações que só preenchiam o lado direito do papel, com espaço suficiente para ser cortado e colado em cartões padronizados (JUVÊNCIO e MEDLEG, 2017).

A bibliografia brasileira, no entanto, é marcada principalmente por interrupções e descontinuidades. Nesse sentido, mesmo o Boletim Bibliográfico da BN, após a morte de Cícero de Brito Galvão, em 1920, sofre uma pausa de mais de uma década, voltando a ser publicado apenas no final de 1930, sobrevivendo até 1982 com este título, para ser então renomeado como Bibliografia Brasileira, até sua extinção, em 1995. Naquele ano, devido a problemas de financiamento, a publicação impressa foi suspensa. Em 1996 e 1997, duas exportações do banco de dados da BN deram origem a duas publicações da Bibliografia Brasileira em CD-Rom, embora estas tenham sido logo interrompidas. Desde 1997, o único acesso à bibliografia brasileira atual, portanto, é possível somente através dos catálogos da própria Biblioteca, disponíveis on-line ${ }^{2}$.

De 1943 a 1945 houve, no campo da bibliografia brasileira, um fenômeno curioso. Enquanto o Instituto Nacional do Livro (INL) preparava os volumes de sua Bibliografia Brasileira e a BN se atrasava na publicação do Boletim Bibliográfico, um bibliógrafo independente, Antônio Simões dos Reis, elaborou 16 volumes de Bibliografia da bibliografia Brasileira, correspondentes aos anos de 1942 e 1943 (REIS, 1942). Adotou o índice alfabético por assunto e incluiu, em cada volume, índices temáticos e onomásticos. Entretanto, seu trabalho foi um fracasso, na medida em que, em um momento em que se assistia a um grande incremento nas publicações e, portanto, na necessidade de trabalhos bibliográficos realizados por equipes, ele tentou reviver tradições bibliográficas antiquadas. Reis, em que pese que as primeiras listas e compilações datem de 1808, considera que somente a partir de 1835 pode-se falar de uma bibliografia brasileira, com o aparecimento de Obras médicas publicadas no Rio de Janeiro ao longo de 1934, no Diário da Saúde (1935). A primeira lista de livros que Simões menciona, no entanto, é o Catálogo de livros encontrados na biblioteca pública da cidade da Bahia, de 1818. Outras publicações tentaram preencher as lacunas de uma bibliografia nacional pouco eficaz, como aquelas produzidas 
pelo INL de 1938 a 1972 e pela União Nacional de Editores de Livros, entre 1963 e 1977. Editoras como a Estantes e a Vozes, entre 1952 e 1981, contribuíram para esse esforço, mas sempre, em todas as publicações, há intervalos mais ou menos longos na periodicidade (CRIPPA, 2018).

José Honório Rodrigues (1913-1987) foi o principal responsável pela realização de uma história da historiografia brasileira: é um nome importante, na bibliografia brasileira, porque foi um dos principais quadros do INL, além de ser, entre 1946 e 1958, o diretor das publicações da seção de obras raras da BN e, entre 1958 e 1964, diretor do Arquivo Nacional. Naquele ano, após o golpe militar, ele foi forçado a deixar seu posto e, em seguida, a se exilar. Rodrigues define bibliógrafo a pessoa que tenha completado uma ou mais bibliografias sobre um determinado tema ou que tenha desenvolvido outras ferramentas bibliográficas, tais como guias, catálogos e índices, que considera importantes para os estudos eruditos da história e das ciências sociais e humanas em geral.

Com a saída de Rodrigues das atividades bibliográficas, o interesse pela bibliografia como campo de reflexão que envolve os campos das humanidades é reduzido em poucos anos, como veremos mais adiante.

O momento que pode ser identificado como a fase "chave" da chegada da documentação no Brasil e, a partir disso, de novas perspectivas para a bibliografia é a criação do Departamento Administrativo do Serviço Público (DASP), em 1939 e, principalmente, do já citado Instituto Brasileiro de Bibliografia e Documentação, IBBD, em 1954, duas instituições que, paulatinamente, incorporam e validam um novo conceito (informação) e uma nova prática científica (Ciência da Informação). Isso é o que discutiremos na próxima seção.

\section{O Instituto Brasileiro de Bibliografia e Documentação (IBBD)}

Os anos da Segunda Guerra Mundial correspondem, grosso modo, ao governo autoritário e populista de Getúlio Vargas, chamado Estado Novo quando, sob o pretexto da ameaça comunista, Vargas realizou um golpe que o manteve no poder de 1937 a 1945. 
Para nossa discussão, é importante focar no aspecto da modernização que a Era Vargas promoveu no Brasil. Modernização significava a possibilidade e a capacidade de dar ao Estado a racionalidade necessária para o seu funcionamento, a fim de poder responder às necessidades administrativas e produtivas da sociedade industrial em desenvolvimento. O Estado Novo estimulou a reformulação da administração pública, com o desenvolvimento da eficiência burocrática, voltada para a qualificação profissional da administração para os interesses nacionais. Dentro desse projeto de modernização burocrática em 1939 foram criados o Departamento de Imprensa e Propaganda (DIP) e o Departamento de Administração do Serviço Público (DASP), para qualificar os quadros representativos de uma administração pública racional e eficiente.

Nessa perspectiva reformadora, Lydia de Queiroz Sambaquy, que completara seus estudos em Biblioteconomia nos Estados Unidos, foi nomeada diretora da biblioteca do DASP (ODDONE, 2006). Gradualmente, sob sua direção, a biblioteca adquiriu corpo, força e visibilidade, desenhando algumas características da biblioteconomia brasileira, estabelecendo modelos próprios, buscando parcerias, construindo redes (ODDONE, 2006).

Em 1951, em São Paulo, foi realizada a Conferência da UNESCO sobre o desenvolvimento de bibliotecas públicas na América Latina, para identificar os problemas dessa tipologia de bibliotecas e para elaborar recomendações em prol de seu avanço. Emerge, como necessidade a ser satisfeita, a exigência da criação de centros bibliográficos e se estabelece a diretriz pela qual todos os países da região deveriam estabelecer centros bibliográficos nacionais, com a função de elaborar as bibliografias nacionais e regionais atuais, de compilar as bibliografias nacionais retrospectivas, de promover essas bibliografias, de preparar um catálogo cooperativo dos recursos bibliográficos para cada país, de compilar guias para fontes de informação, de colaborar, internacionalmente, com a finalidade de compilar uma bibliografia de bibliografias latino-americana, além de realizar a catalogação analítica de periódicos e de publicar os respectivos índices (SAMBAQUY, 1957).

$\mathrm{Na}$ sua apresentação, durante a conferência da UNESCO, publicada posteriormente, Lydia Sambaquy afirma que 
[...] O que importa é que as bibliotecas entendam que, para servir bem, não é necessário somente saber que livros possuem, mas também onde se encontra o livro ou as informações que realmente se buscam [...] É importante que os bibliotecários ou os que organizam as bibliotecas não esqueçam que não podem mais viver isolados e que a cooperação recíproca será com frequência devolvida multiplicada, com taxas de interesse elevadas. [...] (SAMBAQUY, 1953, p. 69).

O apoio da UNESCO foi fundamental para a criação do IBBD, do qual Lydia Sambaquy foi diretora por vários anos. O IBBD foi a instituição responsável pela remodelação da documentação e dos métodos bibliográficos e pela capacitação de pessoal qualificado para os serviços bibliotecários.

Criado o IBBD, por iniciativa de Lydia Sambaquy e Edson Nery da Fonseca, entre os outros bibliotecários que lá trabalhavam, este centralizava os recursos bibliográficos, colocando em primeiro plano (e isso, veremos, será um elemento essencial para entender a direção que os estudos bibliográficos tomarão) a necessidade de acesso à informação para a comunidade científica. Para se ter uma ideia da comunidade científica imaginada pelo IBBD e dos serviços que o Instituto propôs oferecer, recorremos ao próprio Boletim do IBBD, publicado desde 1955. Na primeira edição, Sambaquy escreve que a publicação, produzida pelo principal órgão nacional de informação e documentação, é criada para "[...] promover a troca de informações entre os institutos de pesquisa, no Brasil e no exterior, de obras técnico-científicas brasileiras”. (SAMBAQUY, 1955, p. 1). Assim, destaca as diferentes facetas da ciência, referindo-se aos materiais aos quais o trabalho de documentação permite acesso, desde artigos sobre física nuclear até geografia.

No entanto, por se tratar de um boletim dirigido a bibliotecários, os artigos sobre Biblioteconomia e Documentação ocupam o espaço mais amplo, e é aqui que o papel de bibliotecários e bibliotecas se evidencia, na perspectiva do avanço da pesquisa no Brasil, identificado com um modelo de modernização tecnocientífica então predominante. Assim, o Boletim tinha o propósito de "[...] fornecer notícias atuais e interessantes para a pesquisa bibliográfica registrando o que está acontecendo no mundo científico e tecnológico brasileiro, especialmente o que se relacionas ao trabalho do Conselho Nacional de Pesquisa e das Instituições relacionadas". (SAMBAQUY, 1955, p. 2). Segundo 
Sambaquy, o conceito de um bibliotecário capaz de satisfazer as necessidades da pesquisa científica seria o fil rouge presente em todos os artigos publicados, oferecendo o acesso ao conhecimento da terminologia das áreas em que se encontrasse atuando. O bibliotecário obteria, com essa qualificação, o respeito da comunidade científica e da sociedade em geral.

Para satisfazer as necessidades da comunidade científica, o IBBD incentivou numerosos cursos de especialização, ministrados por bibliotecários de bibliotecas especializadas e por cientistas, que introduziram o conhecimento das ciências físicas, naturais, médicas e tecnológicas (SAMBAQUY, 1957).

O IBBD buscava se tornar o administrador central dos serviços de informação de centros especializados de documentação e centros bibliográficos gerais, para facilitar a pesquisa bibliográfica, tornando o trabalho científico mais viável:

Cabe, pois, ao IBBD incentivar a execução de trabalhos bibliográficos empreendidos pelas diferentes instituições especializadas, e, quando solicitado, participar diretamente desses trabalhos, auxiliando e colaborando ativamente, sempre evitando qualquer duplicação de serviço. Cumpre-lhe, ainda, inventariar as disponibilidades de nossos acervos bibliográficos e envidar os melhores esforços no sentido de uni-los através da mais perfeita cooperação, a fim de que cada estudioso venha a ter permanentemente a seu serviço o total das coleções bibliográficas existentes no País. (SAMBAQUY, 1957, p. 4)

O instituto também tinha a responsabilidade de oferecer assistência técnica para a organização de bibliotecas, de centros de documentação, de prestar assistência na seleção de coleções bibliográficas e, através do Serviço de Intercâmbio de Catálogos (SIC), de contribuir para a catalogação e classificação das bibliotecas.

O Serviço de Bibliografia, que também atuou como editor bibliográfico e coordenador das atividades bibliográficas do país, forneceu ao Serviço de Informação Técnico-Científica as bibliografias brasileiras sobre a produção intelectual nacional no campo científico e tecnológico, necessárias como ferramenta de informação. Era responsabilidade desse Serviço, dividido em duas seções (uma de ciências físicas e naturais e outra de ciências sociais), compilar a bibliografia científica brasileira atualizada e organizar, segundo um programa 
aprovado anualmente, as bibliografias especiais de interesse das instituições de pesquisa.

A biblioteca do IBBD, dirigida por Sambaquy, foi uma das primeiras bibliotecas, no Brasil, dedicada à coleta de coleções, catálogos de bibliotecas, bibliografias nacionais e especializadas, índices e resumos de literatura científica e tecnológica de todos os países, buscando dominar a literatura científica internacional, objetivando informar os estudiosos sobre a pesquisa de ponta realizada no país e no exterior. Um dos princípios do IBBD era realizar a conexão entre as bibliotecas brasileiras para permitir colaborações e intercâmbios, colaborando com todos os meios à disposição para o registro da produção intelectual brasileira. Dessa forma, o IBBD teria contribuído efetivamente para o desenvolvimento da ciência e tecnologia no Brasil.

Lydia Sambaquy foi, como José Honorio Rodrigues, vítima do regime militar, forçada a abandonar a presidência do IBBD no final de 1965. O projeto do IBBD foi adiante, nas mãos de outros bibliotecários até ser substituído pelo Instituto Brasileiro de Informação em Ciência e Tecnologia (IBICT) em 1976, entre cujos fundadores, encontramos Edson Nery da Fonseca, sobre o qual, agora, torna-se necessário aprofundar a discussão. Há fortes indícios que sugerem que na gestão do IBBD a visão de Lydia Sambaquy não coincidiu com a de Edson Nery da Fonseca, e que este tomou as rédeas da bibliografia no Brasil em suas mãos para a partir do momento em que Sambaquy foi removida do IBBD. Um exemplo de pistas e evidências sobre suas discrepâncias pode ser encontrado em declarações como essa:

Os rumos do Instituto brasileiro de Bibliografia e Documentação (IBBD), por exemplo, teriam sido outros, se a orientação do consultor da Unesco, Herbert Coblans, tivesse prevalecido sobre a de Lydia de Queiroz Sambaquy, com quem ele teve debates nada suaves [...]. É claro que tais conflitos não devem perturbar nossa visão do problema. Eles retardam, mas jamais deterão o progresso da ciência, que é inexorável (FONSECA, 2007, p. 7-8).

\section{Edson Nery Da Fonseca e as mudanças na bibliografia no Brasil}

O fim da era Vargas, em 1945, foi seguido por cinco anos de mandatos presidenciais militares. Em 1950 Vargas retorna ao cenário político como 
presidente eleito, iniciando seu mandato sob o signo do nacionalismo: cria a Petrobrás e o Banco Nacional de Desenvolvimento Econômico e Social (BNDES). Alinhada ao pensamento do liberalismo econômico, a União Democrática Nacional (UDN) estabeleceu, ao longo desses anos, a linha que prevaleceria com o golpe militar de 1964. Juscelino Kubitschek assumiu a presidência em 1956 e, no final do mandato, sua reeleição foi impedida. Em 1960, Jânio Quadros foi eleito presidente, mas poucos meses após a eleição, teve o mandato caçado e foi provisoriamente substituído por Ranieri Mazzini, até João Goulart, que fora vice-presidente de Kubitschek e se encontrava exilado, assumir a presidência, que durou três anos, quando manobras políticas e militares desaguaram no Golpe destinado a mudar o país por mais de duas décadas. Dois fatores são importantes para nosso estudo: o primeiro é a manutenção e o incremento dos processos de modernização do país, através da orientação dos recursos de pesquisa para o setor científico e tecnológico, enquanto a segunda, na direção oposta, foi a limitação da liberdade de expressão em todos os níveis, através da imposição de uma forte censura.

Se as razões para a criação do IBBD foram aqui colocadas na perspectiva da política nacional na década de 1950, da mesma forma devemos ver sua transformação no IBICT, com algumas reflexões sobre a transferência dos interesses deste da Biblioteconomia para a nascente Ciência da Informação, durante o conturbado período da história brasileira marcado pela ditadura militar e pelo projeto de desenvolvimento por ela desencadeado. Entender as mudanças que culminaram no regime militar nos permite entender as políticas de informação que este formulou. Como afirmamos em nossa introdução, nossa hipótese é que o poder exercido pelo Estado de exceção é refletido de forma incisiva nas políticas de informação.

A preocupação para com questões de vigilância e de controle sobre a informação durante a ditadura militar levaram, já em 1964, mas com força ainda maior em 1968, a um cenário de perseguição e aprisionamento de quem não fosse considerado alinhado ao regime e de apagamento da memória, através de um aparato de controle da informação que se aplicou a todos os setores da 
sociedade, da educação e da cultura. As instituições ligadas à informação foram controladas pelas estruturas militares, tornando-se instituições rígidas de controle. Vale ressaltar que, além da censura e controle de informações, foi implementada uma política ativa de perseguição de cientistas, pesquisadores e profissionais no mesmo período. Durante a primeira fase da ditadura, entre 1964 e 1967 (sob a presidência de Castelo Branco), o governo reduziu as despesas de pesquisa. No entanto, o projeto modernizador impulsionou a adoção de critérios de seleção no âmbito da educação e da pesquisa, reforçando os interesses de desenvolvimento das ciências exatas e tecnológicas. Um elemento importante nesse sentido foi a criação do Plano Estratégico de Desenvolvimento que, estruturou um programa de políticas científicas nacionais, visando garantir a permanência dos cientistas no país, por meio de investimentos em pesquisa.

Nesse cenário, podemos observar a coexistência de duas dimensões de controle informacional, uma ligada à esfera acadêmica e técnico-científica e a outra ao controle social da informação.

Como vimos, Lydia Sambaquy iniciou seu projeto para desenvolver o sistema de informação técnico-científica em 1938 na biblioteca DASP, para continuar no IBBD. Naquela época, o serviço de troca de catálogos representava uma importante função de cooperação técnica entre as bibliotecas brasileiras.

A participação de Sambaquy em congressos e comitês dedicados ao desenvolvimento científico e tecnológico a levou a compreender o potencial das atividades bibliográficas para o desenvolvimento do Brasil. Oddone (2006), ressaltando o surgimento de um novo regime de informação, afirma que isso estabeleceu as condições e possibilidades para o surgimento futuro da Ciência da Informação no Brasil, a partir de aproximações entre a prática bibliotecária, a Documentação e o conceito de informação científica. O interesse cada vez mais definido pela informação estritamente científico-tecnológica, como descrito acima, além de modificar a seleção relativa aos estoques de informação e conhecimento, fez com que o IBBD participasse de importantes eventos no setor científico, fato que influenciou sua transformação no IBICT em 1976.

Desde sua criação como instituição responsável pela informação científica no Brasil, suas políticas de informação tornaram-se parte dos 
interesses políticos nacionais durante a ditadura militar brasileira, em um contexto projetado para a pesquisa científica internacional. Com a transformação do IBBD no IBICT, o conceito de informação encontra a intersecção de dois aspectos: o primeiro serve a uma política de ciência e tecnologia, enquanto o segundo está a serviço de uma política de segurança distorcida, que favorece um Estado autoritário e marcado por políticas de vigilância, tratando a informação como setor pragmático e estratégico de ação de vigilância e coerção. Ambos os aspectos, além de seus mecanismos específicos, têm pontos de encontro, um dos quais pode ser identificado precisamente no uso que pode ser feito da bibliometria, da qual Edson Nery da Fonseca se tornou porta-voz.

Nascido no Recife em 1921, Edson Nery da Fonseca foi um dos grandes protagonistas da cena bibliográfica e bibliotecária brasileira, sendo, entre outras coisas, o fundador de vários cursos de Biblioteconomia, além da biblioteca central da Universidade de Brasília. Em 1954, ele estava entre os promotores e fundadores do IBBD, como vimos, ao lado de Lydia Sambaquy. No IBBD foi diretor do departamento de Bibliografia desde 1954 dedicando-se ao estudo da bibliografia. De fato, pode-se dizer que é a personalidade que deu o tom às discussões sobre o assunto, através de um conjunto de artigos publicados em várias revistas tanto de Biblioteconomia como de outras áreas. Paradoxalmente, observaremos a seguir como ele tornou-se um dos responsáveis pela limitação da bibliografia como campo de interesse ou, melhor, por sua substituição pela bibliometria, em artigo que marca a história da disciplina, publicado em 1979.

Em 1962, Edson Nery, apontando para os que ele chamou de "especialistas em informação científica", afirmou que

[...] Com a recente verificação de que não basta organizar documentos $[\ldots]$ sendo também necessário analisar-lhes o conteúdo e deles extrair informações, a palavra documentação tornou-se insuficiente. É preciso substituí-la por informação científica. [...] Essa nova profissão é uma exigência da nossa época [...]. A informação científica, como profissão, caracteriza-se [...] [por] atribuições distintas das cometidas ao bibliotecário [...]. Entre bibliotecários e especialistas em informação científica [...] deve haver $[\ldots]$ relações $[\ldots]$ [de] independência e harmonia [...] (FONSECA, 1962, p. 56-57). 
Em 1972, Fonseca escreveu que bibliografias retrospectivas individuais, nacionais, bem como especializadas de interesse para a história da ciência - são importantes mesmo se publicadas com atrasos. As bibliografias atuais, por outro lado, especialmente as especializadas, perdem o interesse quando estão atrasadas. $\mathrm{O}$ aspecto bibliográfico principal para a ciência e a tecnologia é representado pelo resumo de artigos indexados em nível temático. Assim, no mesmo artigo, Fonseca afirma que a Documentação nada mais é do que a Bibliografia modificada em seu conteúdo - resumos de artigos e não apenas referências a livros - e acelerada em sua marcha, isto é, caminhando ao lado dos fatos e até mesmo prevendo-os, por exemplo, através da publicação de pesquisas em andamento e não simplesmente rastreando-as depois que elas foram produzidas. De fato, a Documentação, como elemento propulsor da bibliometria, é de grande importância, especialmente na esfera técnicocientífica. O problema é que o endereço dado por Fonseca, no entanto, é outro. Se, por um lado, a contribuição dos estudos bibliométricos é inegável como parte dos estudos bibliográficos, do outro, no Brasil, assistimos ao progressivo desaparecimento da bibliografia em seu sentido mais amplo, como produção de "mapas" da literatura, como conhecimento acessível aos usuários que se estende a outros estudos bibliológicos. No mesmo artigo citado, Fonseca (1972) argumenta que a Documentação veio resolver um problema para o qual a Biblioteconomia e a bibliografia não se haviam desenvolvido adequadamente. Esse problema era representado pela explosão científica e tecnológica e pelo consequente crescimento exponencial do número de livros e artigos, bem como pelo surgimento de documentos não convencionais, como teses de pósgraduação, relatórios de pesquisa, patentes, seminários, simpósios e outros tipos de reuniões científicas e técnicas (ou seja, a chamada literatura cinzenta).

Isso, no entanto, para Fonseca não significou a substituição da Biblioteconomia pela Documentação, pois a primeira teria outras funções com as quais a última não deveria se preocupar em lidar, como a democratização da cultura através de bibliotecas públicas, a preservação e disseminação do patrimônio bibliográfico nacional, através da $\mathrm{BN}$ e o apoio documental para ensino e pesquisa em nível mais amplo através de bibliotecas escolares e 
universitárias. Inicialmente, a Documentação dizia respeito à padronização ou utilização de normas nos processos de organização e disseminação de documentos: classificação, indexação temática, resumos, divulgação através de publicações, chamadas secundárias, etc. Também era necessário normalizar a produção de publicações primárias - apresentação de originais, publicação de livros e periódicos etc. Em suma, facilitar o processamento da informação. Para Fonseca (1972), então, podemos dizer que a Ciência da Informação nasceu quando se tornou necessário não só coletar, classificar e disseminar documentos, mas também estudar como as informações neles contidas surgem e se transformam.

Referindo-se à abertura de uma conferência internacional sobre Biblioteconomia e Bibliografia, realizada em Madri, em 1935, Fonseca (1971) cita a previsão de Ortega y Gasset sobre a possibilidade de uma técnica bibliográfica, um automatismo rigoroso que tornaria fácil verificar quando e onde uma ideia se transforma e o momento em que (des)aparece no horizonte da história. Ortega y Gasset, para o autor, é quem lançou as bases teóricas da Ciência da Informação e uma de suas principais ferramentas, a bibliometria.

Esse processo é claramente delineado em outro artigo dedicado à função da bibliografia, no qual Fonseca (1979) parece estabelecer os parâmetros da disciplina de maneira clara. Em nossa opinião, o artigo reflete completamente a construção de políticas de informação no contexto do regime militar que discutimos. O artigo de Fonseca estabelece, de maneira bastante positivista e problemática, o caminho que deve ser seguido pela bibliografia.

Como vimos, em algumas de suas publicações (1971, 1972 e 1973) Fonseca estabeleceu que, como ferramenta indispensável para a pesquisa e o desenvolvimento científico e tecnológico, a bibliografia era objeto de preocupação para os estudiosos que buscavam aperfeiçoar técnicas e métodos para uma melhor compreensão, controle e disseminação do material bibliográfico existente mas, acima de tudo, ele havia afirmado que a literatura produzida por "cientistas da informação" era baseada em pesquisa, enquanto a de bibliotecários e documentalistas se limitava à aplicação dos resultados obtidos de tais investigações. Para Fonseca, portanto, a Ciência da Informação 
incluía, ao lado dos trabalhos experimentais, também os resultados práticos da aplicação de técnicas e métodos que contribuíam para o desenvolvimento de atividades de informação científica. Nesse sentido, Fonseca pode ser visto como um dos responsáveis pela "fissura" que se cria, no Brasil, entre a Ciência da Informação - voltada ao progresso - e a Biblioteconomia, teoricamente validada para atuar em bibliotecas públicas mas que, na verdade, acabou perdendo sua função de "democratização" do conhecimento na medida em que a política nacional se tornou de vigilância mais estrita da informação, através da censura e da coerção. Fonseca (1979), em seu artigo A bibliografia como ciência: da crítica textual à bibliometria, estabelece qual deve ser o papel e a função da bibliografia no contexto histórico em que o IBICT é criado.

Neste artigo, ele define os parâmetros da disciplina de maneira clara. Como princípio, o autor afirma que a pesquisa bibliográfica tem como objetivo buscar livros e artigos sobre determinados temas e autores. Ressaltamos aqui que, em 1971, ele já havia considerado a literatura cinzenta como perniciosa, definindo, por exemplo, os resultados de palestras científicas em termos de "anti-publicações" e "semi-publicações" (FONSECA, 1971, p. 144), considerando-os perigosos enquanto obras que "não merecem [...]ser preservadas nos arquivos da ciência” (FONSECA, 1971, p. 144). No mesmo artigo, ele também criticara a inclusão de livros como sendo de pouca utilidade para a prática científica, porque sua produção exigia muito tempo e isso afetava o ritmo da pesquisa: "O atraso do livro tradicional é da ordem de 2 ou 3 anos: portanto, claramente superior ao dos periódicos" (FONSECA, 1971, p. 145).

Em 1979, pretende mostrar que a bibliografia é mais do que uma pesquisa: é uma atividade que pressupõe hipóteses claramente formuladas e objetivamente testadas. Se, por um lado, não podemos discordar da ideia de que a bibliografia é mais que uma simples busca de materiais, por outro lado parece claro que as propostas desenvolvidas naqueles anos são, paradoxalmente, mais redutoras do que nunca. Fonseca, de fato, usando uma paráfrase do poeta brasileiro Manuel Bandeira, afirma estar "cansado desta bibliografia atrofiada, sifilítica e subdesenvolvida, com seus repertórios, arquivos e discussões bizantinas de Johann Tritheim ou Conrad Gesner [sic], Cuja Obras nunca foram 
vistos entre nós "(FONSECA, 1979, p. 30). Nesta afirmação, no entanto, a presença histórica desses autores nas bibliotecas eclesiásticas brasileiras é eliminada de uma só vez.

$\mathrm{O}$ autor segue propondo o que ele chama de "anti-bibliografia", com a finalidade de eliminar o que ele define "seu aspecto de pura técnica ou mesmo de simples ciência auxiliar, para ressaltar sua condição de ciência com objetivos próprios, talvez mais válida, como tal, do que a própria biblioteconomia." (FONSECA, 1979, p. 30). Ele então elabora uma breve história de autores, com referências especialmente anglófonas (incluindo Pollard, McKerrow, Greg), para concluir que eles eram os herdeiros diretos dos bibliotecários de Alexandria. Essa pseudo "genealogia" alexandrina serve ao autor para argumentar que a bibliografia deve realizar uma "crítica textual", comparando essas operações às de Mendel no campo da genética, na medida em que as edições subsequentes de uma obra funcionariam como uma transmissão hereditária. Fonseca, na realidade, com sua referência ao "brasão" como árvore genealógica dos "códigos", não faz senão propor o que já faz parte das disciplinas filológicas, aqui propostas como operações que sustentariam uma maior cientificidade que a bibliografia como era entendida. Nessa parte de seu artigo, mistifica a bibliografia falando sobre operações filológicas como se elas constituíssem uma inovação bibliográfica, ao invés de estabelecer parâmetros de atividades efetivamente bibliográficas: na realidade, nesta parte de sua proposta, acaba trazendo-a de volta para outra disciplina auxiliar, embora sem citar qual é essa última, precisamente a filologia. De fato, essa proposta de Fonseca não é destinada a se tornar o caminho vital para sua proposta "científica" da bibliografia. Proposta, porém, que ele explicita sem titubear na segunda parte de seu artigo, aquela que vinha sendo construída desde a época em que atuava no IBBD e que está presente em seus escritos sobre a necessidade de uma comunicação científica decorrente da documentação e "aliviada" dos tempos demasiadamente longos das compilações bibliográficas. É a bibliografia destinada a substituir quase por completo a busca representada pela complexidade bibliográfica através da velocidade e da eficácia da bibliometria. 
É, este, um aspecto da elaboração de Fonseca que busca tornar a bibliografia uma prática por ele definida "científica", derivando-a da bibliografia estatística de origem anglo-saxônica e da obra de Otlet. A nosso ver, essa perspectiva tem sustentado até tempos recentes o arcabouço epistemológico (e os problemas) da Ciência da Informação brasileira.

\section{Algumas considerações finais}

Na centralidade da bibliometria, identificada como micro e macro bibliografia, Fonseca se coloca como um dos pontos de origem do que, no Brasil, é a espinha dorsal da Ciência da Informação, vista como análise das citações que identificam as redes que a constituem. É inegável que Fonseca é um autor de notável relevância, basta observar nos artigos sobre temas relacionados à bibliometria para encontrar como, até hoje, ele é mencionado. A estrutura de produção, de alguma forma ligada à bibliografia, no Brasil dos últimos anos do século XX, deriva em boa parte de proposições desse autor ou próximas às suas visões, proposições que alavancam, principalmente, os estudos e as análises bibliométricas como ferramenta científica "príncipe", capaz de substituir qualquer outra atividade bibliográfica. Os dados bibliométricos passam assim a serem utilizados como indicadores da produção científica para o planejamento nacional das atividades de pesquisa científica, além de serem utilizados para a análise do desenvolvimento da pesquisa científica e tecnológica dentro de uma instituição específica, para análise de revistas em uma área específica e, finalmente, para calcular a produtividade dos pesquisadores.

A bibliografia enquanto bibliometria tem como objetivo, nessa configuração ligada à velocidade dos dados técnico-científicos coletados, a comprovação ou a retificação da história das ideias, tanto pela relação entre documentos, quanto para o censo ideológico das publicações nacionais. Desta forma, podemos ver como nossa hipótese inicial de uma relação próxima entre políticas autoritárias, políticas de investimento científico e políticas de informação se desenvolveu de maneira bastante entrelaçada.

Vimos como, a partir da visão de "Modernidade", primeiramente no âmbito do Estado Novo de Getúlio Vargas já nos anos 40, em seguida com a 
criação do IBBD e, finalmente, com as políticas técnico-científicas da Ditadura por mais de vinte anos, as escolhas feitas no campo da informação, levaram a investimentos em pesquisa que, embora aparentemente alinhados a um processo internacional de adoção de instrumentos bibliométricos, têm reduzido progressivamente ao estudo da bibliografia enquanto elemento de mediação entre a produção de todos os saberes e os públicos de usuários que se encontram fora dos âmbitos bastante restritos da produção das pesquisas científicas de ponta. Por exemplo, através das afirmações sobre a literatura cinzenta como não confiável, observa-se que, com o desaparecimento das mesmas bibliografias nacionais da $\mathrm{BN}$ nos anos 90, muitos elementos que deveriam compor mapas de conhecimento foram de alguma forma perdidos. Com tudo isso colocado, foi possível pensar em uma série de outras investigações como, por exemplo, sobre a elaboração dos princípios da Ciência da Informação no Brasil para as quais nos referimos a outras publicações realizadas ou em fase de elaboração.

Além de construir um mapa ordenado dos recursos que especificam e substanciam documentos, a bibliografia também deve poder ser atravessada por critérios de pesquisa, e isso é tradicionalmente refletido em autores, obras e edições. Para Serrai (2001), a Bibliografia é a mãe de todas as disciplinas responsáveis pela organização e estruturação da comunicação escrita - passado e presente, registrada e transmitida.

\section{Referências}

ARAUJO, Carlos Alberto. Bibliometria: evolução histórica e questões atuais. Em Questão, Porto Alegre, vol.12, n. 1, p. 11-32, Jan/Jun 2006. Disponível em: https://seer.ufrgs.br/EmQuestao/article/view/16r. Acesso em: 30 mar. 2019.

BALSAMO, Luigi. La bibliografia: storia di una tradizione. 2.ed. Milano: Unicopli, 2017.

CABRAL, Alfredo do Valle. Annaes da Imprensa Nacional do Rio de Janeiro de 1808 a 1822. Rio de Janeiro. Typographia Nacional: 1881. Cadernos do Centro de Pesquisas Literárias da PUCRS, Porto Alegre, v. 4, n. 3, 1998.

CALDEIRA, Ana Paula Sampaio. Ramiz Galvão e a ideia de biblioteca como vitrine da nação: modelos europeus e trocas culturais no processo de modernização da biblioteca nacional. História, São Paulo, v. 36, e 24, 2017. 
Disponível em: http://www.scielo.br/pdf/his/v36/1980-4369-his-36-e24.pdf. Acesso em: 04 abr. 2019.

CRIPPA, Giulia. Looking for the lost bibliography. The Brazilian case. Bibliothecae.it, Bologna, v. 7, n. 2, 2018.

FONSECA, Edson Nery da. Desenvolvimento da Biblioteconomia e da Bibliografia no Brasil. Revista do Livro, Rio de Janeiro, v. 2, n. 5, p. 95-120, 1957.

FONSECA, Edson Nery da. Informação científica: uma nova profissão. Ciência e Cultura, São Paulo, v. 14, n. 1, p. 56-57, 1962.

FONSECA, Edson Nery da. Problemas da comunicação da informação científica. Revista do Serviço Público, Rio de Janeiro, n.1, p. 137- 148, 1971.

FONSECA, Edson Nery da. Bibliografia Brasileira Corrente: Evolução e Estado Atual do Problema. Ciência da Informação, Brasília, v. 1, n. 1, p. 9-14, 1972.

FONSECA, Edson Nery da. Bibliografia Estatística e Bibliometria: Uma Reivindicação de Prioridades. Ciência da Informação, Brasília, v. 2, n. 1, p. 57, 1973. Disponível em:

http://www.brapci.inf.br/_repositorio/2011/06/pdf_b67fa51e01_0017043.pdf. Acesso em: 10 abr.2019.

FONSECA, Edson Nery da. A bibliografia como ciência: da crítica textual à bibliometria. Revista brasileira de biblioteconomia e documentação, São Paulo, v. 12, n. 1/2, p. 29-38, jan/jun 1979.

FONSECA, Edson Nery da. Introdução à biblioteconomia. Brasília: Briquet de Lemos, 2007.

JUVÊNCIO, Carlos Henrique; MEDLEG RODRIGUES, Georgete.

Contribution to the history of documentation in brazil: the brazilian national library and its relationship with the international institute of bibliography,

Brazilian Journal of Information Studies: Research Trends, Marília, v. 11. n. 1, p. 1-9, 2017. Disponível em:

http://www2.marilia.unesp.br/revistas/index.php/bjis/article/view/5041. Acesso em: 20 abr. 2019.

LAFAYE, Jacques. Albores de la imprenta: el libro en Espana y Portugal y sus posesiones de ultramar (siglos XV y XVI). Mexico, D.F: Fondo de Cultura Econômica, 2002.

MORAES, Rubens Borba de. Livros e bibliotecas no Brasil colonial. Brasilia: Briquet de Lemos, 2006. 
ODDONE, Nanci. O IBBD e a informação científica: uma perspectiva histórica para a ciência da informação no Brasil. Ciência da Informação, Brasília, v. 35, n. 1, p. 45-56, jan./abr. 2006. Disponível em:

http://www.scielo.br/pdf/ci/v35n1/v35n1a06.pdf. Acesso em: 23 mar. 2019.

OLIVEIRA, Eliane B.; MEDLEG, Georgete R.; CASTRO, Raissa M. A memória na Ciência da Informação: uma análise da produção científica brasileira. Oliveira, Eliane B. e Medleg, Georgete (orgs.). Memória: interfaces no campo da informação. Brasília: UnB, 2017. p. 79-108.

REIS, Antônio Simões dos. Bibliografia da bibliografia brasileira. Rio de Janeiro: Instituto Nacional do Livro, 1942.

SAMBAQUY, Lydia de Queiroz. Catalogación cooperativa y catalogación centralizada. In: DESARROLLO DE LAS BIBLIOTECAS PÚBLICAS EN AMÉRICA LATINA: CONFERENCIA DE SÃO PAULO 1951, São Paulo. Annales [...] Paris: Unesco, 1953. p. 63-70.

SAMBAQUY, Lydia de Queiroz. A razão de ser deste Boletim. Boletim IBBD, Brasília, v. 1, n. 1, p. 1-2, 1955.

SAMBAQUY, Lydia de Queiroz. O IBBD e os serviços que se propõe a prestar. Brasília: CNPq/IBBD, 1957.

SCHWARTZ, Lilia Moritz. A longa viagem da biblioteca dos reis: do terremoto de Lisboa à Independência do Brasil. São Paulo: Companhia das Letras, 2002.

SERRAI, Alfredo. Il cimento della Bibliografia, Milano: Sylvestre Bonnard, 2001.

TOTA, Pedro. O imperialismo sedutor: a americanização do Brasil na época da Segunda Guerra. São Paulo: Companhia das Letras, 2000.

\title{
The development and interweaving between bibliography, bibliometrics and politics in Brazil
}

\begin{abstract}
This article aims to study the course and the current state of bibliographic studies in Brazil, based on the proposition that the nature of the bibliography, which characterizes it in a disciplinary and critical sense, is not limited to being an enumeration of documents or to serve as a schema of their reality in the system, but must also serve as a map to be consulted in relation to them. For this, it was necessary to reconstitute the historical context that allows the understanding of the relationship between national policies and information policies throughout the twentieth century. In this way, we have discovered that
\end{abstract}


the investment choices that focused almost exclusively on scientifictechnological research have made bibliometrics the privileged form of study and bibliographic application in the country until at least the first years of the $21 \mathrm{st}$ century. In this research, carried out by the historical inquiry of the sources, some of the great protagonists of the processes of implantation of the bibliographical and bibliometric methodologies, such as Lydia Sambaquy and Edson Nery da Fonseca, were found and treated. Our hypothesis is that, since the Estado Novo era, there has been an evident and explicit interweaving between national policies aimed at scientific visions of modernization and information policies.

Keywords: Bibliography. Bibliometrics. Lydia Sambaquy. Edson Nery da Fonseca. Information Policies.

Recebido: 30/04/2019

Aceito: 19/06/2019

\footnotetext{
${ }^{1}$ http://www.cultura.gov.br/pnll

${ }^{2}$ http://catalogos.bn.br
} 